\title{
Less than Partial Clinical Response
}

National Cancer Institute

\section{Source}

National Cancer Institute. Less than Partial Clinical Response. NCI Thesaurus. Code C151961.

A change towards improvement from the pretreatment baseline, but not meeting the criteria for complete response or partial response. 